\title{
Possibilidades de incorporação do processamento do cumbaru do assentamento Facão, Furna São José, na cadeia produtiva do turismo rural: estudo de caso na fronteira Brasil/Bolívia
}

The cumbaru processing from Facão, Community San Jose rural settlement possibilities of incorporating, in the production chain of rural tourism: a case study in the Brazil/Bolívia

\section{Possibilités d'incorporation de le traitement cumbaru de la règlement Facao/ la communauté St Joseph dans le le emplacement développement de tourisme dans la chaîne de production du tourisme rural: une étude de cas en frontière Brésil/Bolivie}

Posibilidades de incorporación el procesamiento cumbaru del asentamiento Facao/ comunidad de San José, en la cadena de producción de turismo rural:un estudio de caso en el Brasil/Bolivia

\author{
Marcela de Almeida Silva* \\ Ronaldo José Neves* \\ Sandra Mara Alves da Silva Neves*
}

Recebido em 15/02/2016; revisado e aprovado em 30/08/2016; aceito em 27/10/2016

DOI: http:/ / dx.doi.org/10.20435/1984-042X-2016-v.17-n.4(04)

\begin{abstract}
Resumo: Objetivou-se investigar o potencial agregador dos produtos diferenciados produzidos no assentamento Facão/ Furna São José, pelo grupo "Amigas do Cerrado", para sua incorporação na cadeia produtiva do turismo local. Procedeu-se à pesquisa bibliográfica; a trabalho de campo com registro fotográfico; a estudo de caso e matriz SWOT para análise. Há possibilidade de incorporação dos produtos diferenciados produzidos pela agroindústria investigada, constituindo para a comunidade outra vertente de geração de renda, emprego e melhoria na qualidade de vida dos envolvidos.
\end{abstract}

Palavras-chave: produção de alimentos; Dipteryx alata; turismo rural; desenvolvimento local.

Abstract: The objective was to investigating the potential aggregator of differentiated products produced in settlement Facão/Furna São Jose, by the group "Friend of the Cerrado", to their incorporation in the productive chain of local tourism. Bibliographic search was carried out; field work with photographic record; case study and SWOT matrix for analysis. There is possibility of incorporation of differentiated products produced by agroindustry investigated, providing to the community another strand of income generation, employment and improvement in the quality of life of those involved.

Key words: food production; Dipteryx alata; rural tourism; local development.

Résumé: L'objectif de l'enquête sur l'agrégateur de potentiel de produits différenciés produite dans la Facao/ communauté St Joseph, par le groupe des "Amis de la Cerrado", leur incorporation dans la chaîne de production du tourisme local. Recherche bibliographique a été effectuée; travail sur le terrain avec un dossier photographique; étude de cas et la matrice SWOT pour l'analyse. Il y a possibilité d'incorporation de produits différenciés, produites par l'industrie agroalimentaire étudiée, fournir à la communauté un autre volet de la génération de revenus, l'emploi et amélioration de la qualité de vie des personnes concernées.

Mots-clés: la production alimentaire; Dipteryx alata; le tourisme rural; développement local.

Resúmen: El objetivo de investigar el potencial agregador de productos diferenciados producidos en el Facão/comunidad de San José, por el grupo "Amigos del Cerrado", para su incorporación em la cadena productiva del turismo local. Búsqueda bibliográfica se llevó a cabo; trabajo de campo con registro fotográfico; estudio de caso y matriz DAFO para el análisis. Hay posibilidad de incorporación de productos diferenciados, producidos por agroindustrial investigado, proporcionar a la comunidad otro filamento de la generación de ingresos, el empleo y la mejora en la calidad de vida de las personas involucradas.

Palabras clave: La producción de alimentos; Dipteryx alata, el turismo rural; de desarrollo local.

*Universidade do Estado de Mato Grosso (UNEMAT), Cáceres, Mato Grosso, Brasil. 


\section{INTRODUÇÃO}

A agricultura familiar vem passando por várias mudanças em seus aspectos estruturais e, nos últimos anos, vem sendo foco de debates em diversas áreas do conhecimento. Esse interesse é devido à representatividade que esse setor tem mostrado na produção e reprodução socioeconômica e cultural, valoração do homem do campo, desenvolvimento da economia solidária, dentre outros. Assim sendo, a agricultura familiar destaca-se pela produção de alimentos, geração de empregos e renda no campo, representando cerca de $70 \%$ da ocupação de terra e estabelecimentos rurais no Brasil, sendo tratada como um novo setor econômico (GRAZIANO DA SILVA, 1981; ALENTEJANO, 1999; SCHNEIDER, 1999).

Atualmente, a perspectiva que se vislumbra, e pode ser o aspecto mais desafiador para a agricultura familiar, é como aumentar a produção de alimentos, gerando novas ocupações produtivas, melhorando o nível de renda recebida, de modo que amplie o poder de negociação dos agricultores nos mercados, cada vez mais globalizados (PESSANHA, 1998; SILVA et al., 2010). Nos mercados globalizados, há uma demanda pelo aumento da escala de produção, e, para que os agricultores familiares consigam se inserir nos mercados, tem sido necessário o uso de tecnologias e qualificação para a transformação dos excedentes produzidos.

Nesse contexto, os agricultores familiares, para manterem-se no campo, passaram a adotar nova ótica de sustentação econômica, pautando-se na pluriatividade, dando uma nova roupagem às antigas atividades desempenhadas nas comunidades, adotando uma nova estrutura como estratégias reprodutivas. Esta estaria assim, apontando para novos processos de exploração agrícola (denominadas de atividades não agrícolas), uma atividade cujo desenvolvimento local pode assumir um peso diferenciado na renda complementar familiar, trazendo consigo novos mecanismos que contribuam significativamente para a melhoria da qualidade de vida dos envolvidos (KASHIMOTO et al., 2002; MIOR, 2005; 2007).

O processamento de alimentos nas propriedades dos agricultores familiares despontou-se com estratégia para geração de renda complementar. A partir de então, a constituição de agroindústrias rurais passaram a ser vista como um processo de reconfiguração dos produtos artesanais, desenvolvido na unidade familiar, que possui um caráter agregador de valor aos produtos, organizações associativas com o apoio do poder público. Mior (2005) tratou a agroindústria familiar rural, como sendo uma forma de organização em que a família rural produz, processa e/ou transforma parte de sua produção agrícola e/ou pecuária excedente de sua subsistência, visando, sobretudo, à produção de valor para a comercialização e desenvolvimento dessa comunidade.

Nessa ótica, a Secretária de Agricultura Familiar do Ministério do Desenvolvimento Agrário (SAF/MDA [BRASIL, 2003]) destacou que o fato de a agricultura familiar ser pluriativa é uma característica importante em termos de diversificação produtiva, pois ela proporciona um fluxo de renda mais regular ao longo do ano de modo que reduz a instabilidade do agricultor, ampliando ainda a possibilidade de desenvolvimento de outras atividades e do local.

Nesse cenário de produção, reprodução e comercialização, as mulheres ganham espaço como sujeitos sociais desse processo, dentro dos grupos familiares e sociais da comunidade, sendo estas as responsáveis, na maior parte dos casos, pela elaboração e comercialização dos produtos junto aos pontos de comércio. Rocha et al. (2012) e Siliprandi e Cintrão (2011) indagam que a questão de gênero apresenta uma nova inserção social da mulher do campo, a qual, além de mãe, 
esposa e do lar, passa a ser geradora de sua própria renda advinda da reprodução social, agroindustrialização e comercialização desses produtos. Assim, houve uma mudança no padrão estrutural da família, a individualização para a complementação de renda, sem provocar conflitos na base da unidade familiar.

De fato, o desenvolvimento da comunidade é parte de um processo dinamizador do local, que, de forma geral, passa pela reativação da economia e todo o seu progresso de qualidade de social, cultural e ambiental, desde que possibilitem o encontro coletivo e relações de afetividade; portanto, refere-se ao lugar onde a vida se desenvolve em todas as suas dimensões (sociais, econômicas e culturais) (ÁVILA, 2000; YORI, 2000; LE BOURLEGAT, 2000; CASTILHO et al., 2009).

Assim, as políticas públicas são promovidas no intuito de fomentar e ampliar os recursos locais através de linhas de créditos, destinação e comércio de produtos gerados no âmbito das comunidades rurais. Dentro dessa perspectiva, houve também o estímulo ao desenvolvimento de atividades paralelas à agricultura convencional, como por exemplo, a denominada pelos Ministérios do Turismo (MTur) e Ministério Desenvolvimento Agrário (MDA), como Turismo Rural na Agricultura Familiar (TRAF), que é realizado no espaço da propriedade rural (BRASIL, 2003).

Mariani et al. (2014) afirmaram que o produto da atividade turística possui características intrínsecas ao local em que está inserida e possui uma capacidade dinâmica que abrange diversos segmentos e setores que atendem o turista, agregando resultados positivos na economia local, possibilitando apropriar das características do local, do recurso humano, físico e econômicos para a promoção do desenvolvimento local.

Rodrigues (1999) afirmou que o turismo trata-se de um fenômeno transdisciplinar que impacta os setores: eco- nômicos, sociais, políticos, culturais e ambientais. Além disso, a atividade turística é uma geradora de divisas no país com um montante aproximado de R $\$ 52$ bilhões para o ano 2013 (BRASIL, 2014).

A Organização Mundial do Turismo (OMT) salienta que o turismo tem despontado como a segunda maior atividade econômica do mundo em geração de divisas e empregos, ficando atrás apenas da indústria petrolífera. Combinando atividades diretas e indiretas do setor de viagens e turismo, atualmente representa cerca de 9,2\% do Produto Interno Bruto (PIB) global, mesma proporção dos investimentos mundiais, e 4,8\% das exportações do planeta. O Brasil ficou em $7^{\circ}$ lugar no ranking das Américas e em $28^{\circ}$ no ranking geral ano de 2015 , período entre Copa do Mundo e Olímpiadas 2016.

O estado de Mato Grosso não difere desse cenário, apresentando o Pantanal com polo de atratividade turística. Dentro da política de planejamento do Estado, visando aos próximos 20 anos (MT+20 - 2006-2026), as regiões de planejamento mato-grossense apresentam-se com potencial para o desenvolvimento do turismo cultural, ecoturismo, antropológico, gastronômico, de lazer, entretenimento e de negócios (MATO GROSSO, 2012).

Na região sudoeste mato-grossense, o turismo tem se despontado como uma fatia da economia regional, pautada efetivamente no turismo de pesca, tendo como produtos visitas e passeios no Pantanal e participação em eventos pontuais. Nesse cenário, destaca-se o município de Cáceres, que desenvolve há vários anos o evento que é considerado o festival internacional de pesca esportiva, que tem, na prática da atividade pesqueira, cunho mais econômico que socioambiental (NEVES et al., 2011).

Entretanto o que se observa é que, nessa região, há apenas iniciativas e possibilidades de desenvolvimento de outras modalidades da atividade turística, havendo a necessidade de planejamento 
socioeconômico e ambiental, para que ocorra a incorporação de novos agentes sociais, nesse novo arranjo produtivo. $\mathrm{O}$ município de Cáceres, nesse contexto, por fazer parte da política do governo federal - 65 municípios indutores do turismo encontra-se em processo de organização da atividade turística, mais precisamente direcionando o foco de desenvolvimento local, através do segmento do turismo rural. E esse município, polo da região sudoeste, direciona suas ações no intuito de criar mecanismos alternativos para o desenvolvimento e integração dos demais municípios da região.

$\mathrm{O}$ assentamento Facão/Furna São José, sediado no município de Cáceres, foi selecionado para este estudo, dentre os mais de 67 assentamentos da região sudoeste mato-grossense, por possuir produção diferenciada de alimentos derivados do extrativismo do cumbaru - fruto do bioma Cerrado - que se apresenta como elemento agregador de possibilidades e alternativas para o desenvolvimento da cadeia produtiva local, localização estratégica e organização social, o que amplia as possibilidades de sucesso da atividade.

Assim, o portal Caatinga Cerrado (s/d) das comunidades ecoprodutivas que promovem a sociobiodiversidade destaca que esse tipo de produto:

É o mercado de nicho. É o mercado que atribui um valor aos produtos pelas suas características diferenciadas daqueles que são produzidos em grande escala, ou seja, produtos que possuem identificação de origem, diferencial orgânico, oriundos da sociobiodiversidade ou do comércio justo etc. (CAATINGA CERRADO, s.d., s.p.).

Nesse sentido, o processamento do cumbaru para aproveitamento na produção de alimentos, desenvolvido neste assentamento, é uma forma de os assentados agregarem valor a sua produção de alimentos, e este, inserido na cadeia produtiva do turismo, por ser produto diferenciado, pode ser alternativa para a comunidade obter melhoria nas condições socioeconômicas e qualidade de vida, geração de emprego e renda. Proporciona, assim, opções de consumo e comercialização em outros mercados e apresenta-se como mecanismo à possibilidade de desenvolvimento local. Portanto este estudo teve, como escopo, investigar a possibilidade de incorporação dos produtos diferenciados, desenvolvidos na agroindústria alimentícia do assentamento Facão/Furna São José, pelo grupo de mulheres Amigas do Cerrado, na cadeia produtiva do turismo local.

\section{METODOLOGIA}

O assentamento Facão/Furna São José (Figura 1) está localizado na mesorregião do Alto Pantanal, no município polo da região VII de planejamento do Estado de Mato Grosso, Cáceres, na faixa de fronteira Brasil/Bolívia (MATO GROSSO, 2012). O assentamento foi criado em 1998, através da política de reforma agrária do Governo Federal, sendo divido em lotes de 10 a 40 hectares, onde vivem 40 famílias.

A base econômica desse assentamento pauta-se na agricultura de subsistência e comércio dos excedentes, especificamente das culturas da mandioca, banana e milho; na pecuária, com a criação de gado leiteiro e de corte; criação de pequenos animais como: galinha, porco, carneiro etc. $\mathrm{O}$ fomento das atividades é obtido pelo acesso às políticas públicas. A transferência de tecnologias e a assistência técnica são realizadas por organizações não governamentais, órgãos do Governo do Estado e sindicatos. 

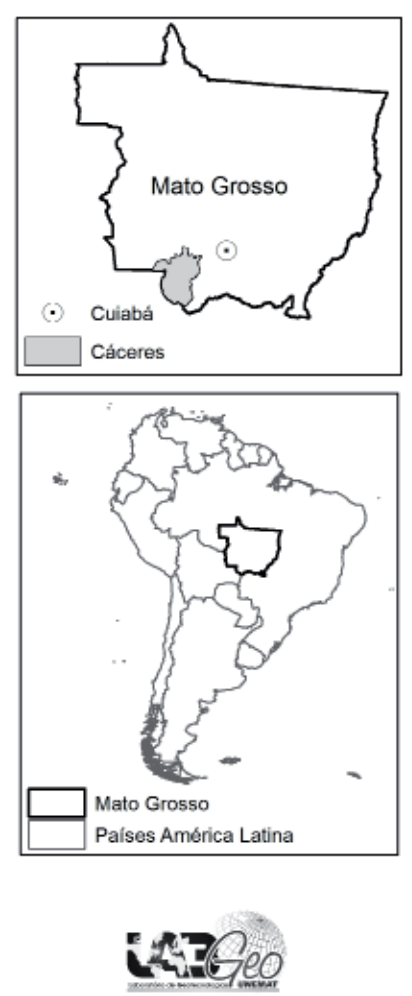

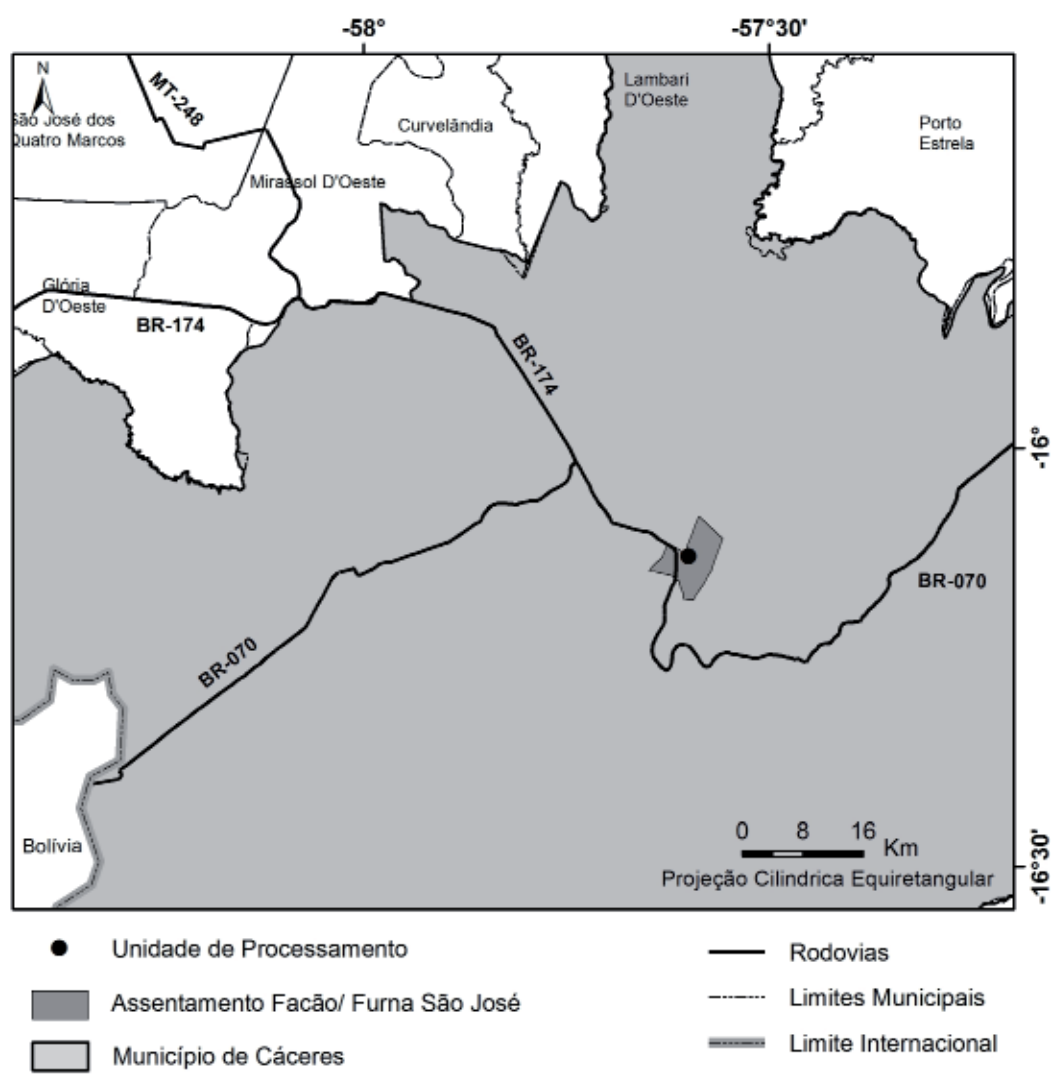

Figura 1 - Localização da área de estudo Fonte: SILVA (2014).

$\mathrm{Na}$ área comum do assentamento, está localizada a unidade de processamento de responsabilidade do grupo de mulheres Amigas do Cerrado, onde são confeccionados os produtos que são comercializados via Companhia Nacional de Abastecimento (CONAB) e prefeituras, através de programas do Governo Federal Programa de Aquisição de Alimentos (PAA) e Programa Nacional de Alimentação Escolar (PNAE), feiras e eventos regionais. Das 40 famílias, 10 desenvolvem a atividade de extrativismo e aproveitamento do fruto do cumbaru na produção de alimentos, oportunizando às famílias envolvidas renda complementar, ao comercializar em feiras, eventos e para consumidores diversos.

Metodologicamente adotou-se o estudo de caso, a pesquisa bibliográfica e pesquisa de campo em 2013, com aplicação de formulário semiestruturado junto a representantes do grupo de mulheres
"Amigas do Cerrado", a partir do qual se geraram os indicadores para a aplicação do na Matriz SWOT; assim como registro fotográfico do processo de produção de alimentos e Sistema de Posicionamento Global (GPS).

A partir dos dados coletados em campo, via formulário e observação, realizou-se a análise de indicadores, aplicou-se a ferramenta matriz SWOT. A ferramenta de análise conhecida como matriz SWOT refere-se à abreviatura de Strengths (Forças), Weaknesses (Fraquezas), Opportunities (Oportunidades) e Threats (Ameaças), que tem a finalidade de avaliar os ambientes internos e externos, possibilitando a formulação e proposição de estratégias de melhoria. Nesta pesquisa, especificamente analisou-se a viabilidade dos produtos diferenciados para a cadeia produtiva do turismo rural local.

Na matriz, para cada indicador identificado em campo, foi atribuído um peso 
e uma nota, relativas às variáveis relevantes ao processamento do fruto e produção dos produtos. Os pesos variaram de zero a um, em que quanto mais próximo de um, maior a relevância, e o inverso (zero) teria menor relevância. As notas variaram numa escala de um a três, sendo que estas corresponderam ao grau de importância, sendo: 1 = pouco importante, 2 = importante e 3 = muito importante (MELO, 2011; MARIANI et al., 2014).

Posterior a esse processo, gerou-se uma nota ponderada, produto do peso e da nota. Desse modo, foram identificados os pontos de maior relevância da produção gerada pelo grupo "Amigas do Cerrado", bem como os aspectos que influenciam, direta ou indiretamente, a possibilidade de sua incorporação na cadeia produtiva do turismo local.

3 PRODUÇÃO ALIMENTÍCIA FEITA COM O FRUTO DO CUMBARU: ESTUDO REALIZADO NO ASSENTAMENTO FACÃO/FURNA SÃO JOSÉ

O grupo de mulheres denominado de "Amigas do Cerrado" é constituído por oito mulheres filiadas à Associação Regional de Produtoras Extrativistas do Pantanal (ARPEP), administrada por um fundo rotativo, constituindo uma entidade civil sem fins lucrativos.

Desde 2005, o grupo de mulheres se organizou através de projetos demonstrativos de manejo e processamento do fruto do Cerrado (cumbaru) e, após o grupo formado, receberam, em forma de doação, parte de um lote para a construção da unidade de processamento, local onde são feitos os gêneros alimentícios. O fruto do cumbaru é beneficiado para a produção de alimentos visando atender duas demanda de produção, conforme figura 2.

A coleta do fruto é feita de julho a setembro, que é o período produtivo do cumbaruzeiro; em média são coletados por dia 1.200 unidades/frutos, e são feitas duas coletas por semana, esses frutos são armazenados em sacos para ter matéria-prima sempre disponível para a produção (MENDES, 2012). Parte dessa matéria-prima é armazenada para atender à produção anual, e uma pequena parte é processada no dia em que são produzidos os produtos diferenciados.

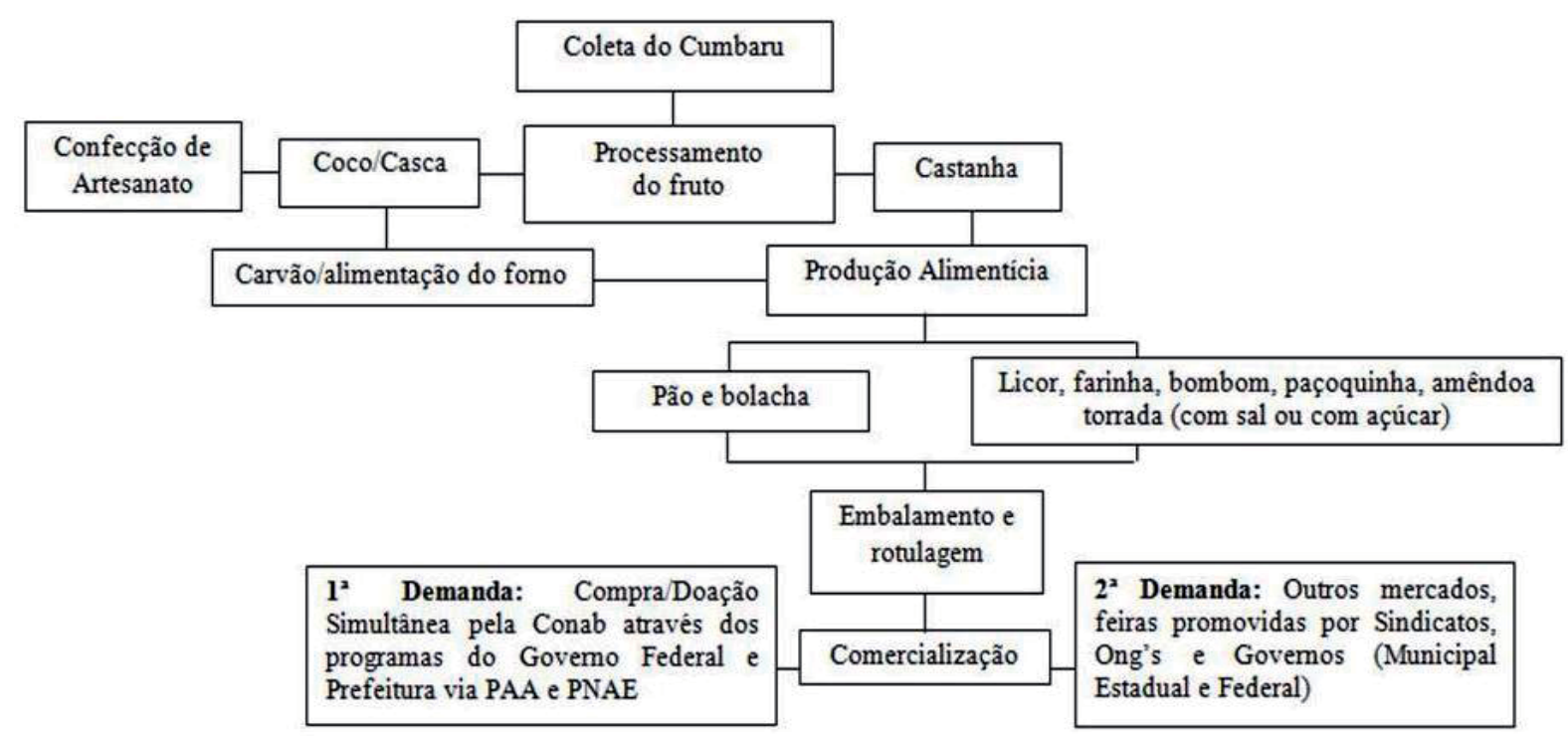

Figura 2 - Fluxograma da produção realizada pelas mulheres do Grupo Amigas do Cerrado 
TogashieSgarbieri (1995) eTakemoto et al. (2001), em estudos sobre o consumo da amêndoa do cumbaru, afirmam que esta é rica em óleo insaturado, proteína, cálcio, fibras alimentares e minerais, sendo boa fonte de macro e micronutrientes essenciais, como potássio, fósforo e manganês, assemelhando-se ao amendoim.

No que tange às demandas da produção, a primeira atende a modalidade compra direta local na linha de compra com doação simultânea que é operacionalizada pela $C O N A B$, através de convênios firmados entre o MDA e os Governos Estadual ou Municipal, que são responsáveis pelo cadastramento das famílias e pela prestação de contas (MATTEI, 2007).

O pagamento é feito diretamente pelo MDA na conta da pessoa que possui a Declaração de Aptidão do Pronaf (DAP), e não é necessária a intermediação de uma organização. As agricultoras (portadoras da DAP) elaboram projetos anuais, para entrega dos produtos (pão e bolacha enriquecidos com cumbaru) para a merenda nas escolas, creches e asilos, no período correspondente ao ano letivo.

A segunda demanda atende outros mercados consumidores, como: feiras locais, regionais e nacionais, realizados por sindicatos, associações, organizações não governamentais e órgãos ligados aos governos Municipal, Estadual e Federal; eventos voltados aos produtores rurais e sob encomenda, onde é comercializado, além da bolacha e do pão enriquecido, o licor, a rapadura, a castanha (torrada com sal ou com açúcar), farinha, sorvete, bolo, barrinha de cereal e bombom de cumbaru, atingindo consumidores da cadeia produtiva do turismo, haja vista que parte da demanda consumidora desses produtos é oriunda de outras cidades.

A produção é feita em etapas estabelecidas pelo grupo, em que cada mulher tem uma função específica, desde a coleta até o produto final. As atividades são divididas de modo que não sobrecarregue nenhuma delas. Dentro deste processo, é feito primeiramente o pão (Figura 3) e, em seguida, a bolacha (Figura 4), para o melhor aproveitamento do aquecimento do forno. Essa produção ocorre todas as terças-feiras, com duração aproximada de 8 a 10 horas, e grande parte do processo é feito manualmente ou empregadas ferramentas desenvolvidas especificamente para facilitar o processo de produção, como por exemplo, o quebrador dos frutos, que quebra em média $2 \mathrm{~kg}$ de fruto por dia, que é a quantidade necessária para a produção, ou variando de acordo com a demanda.
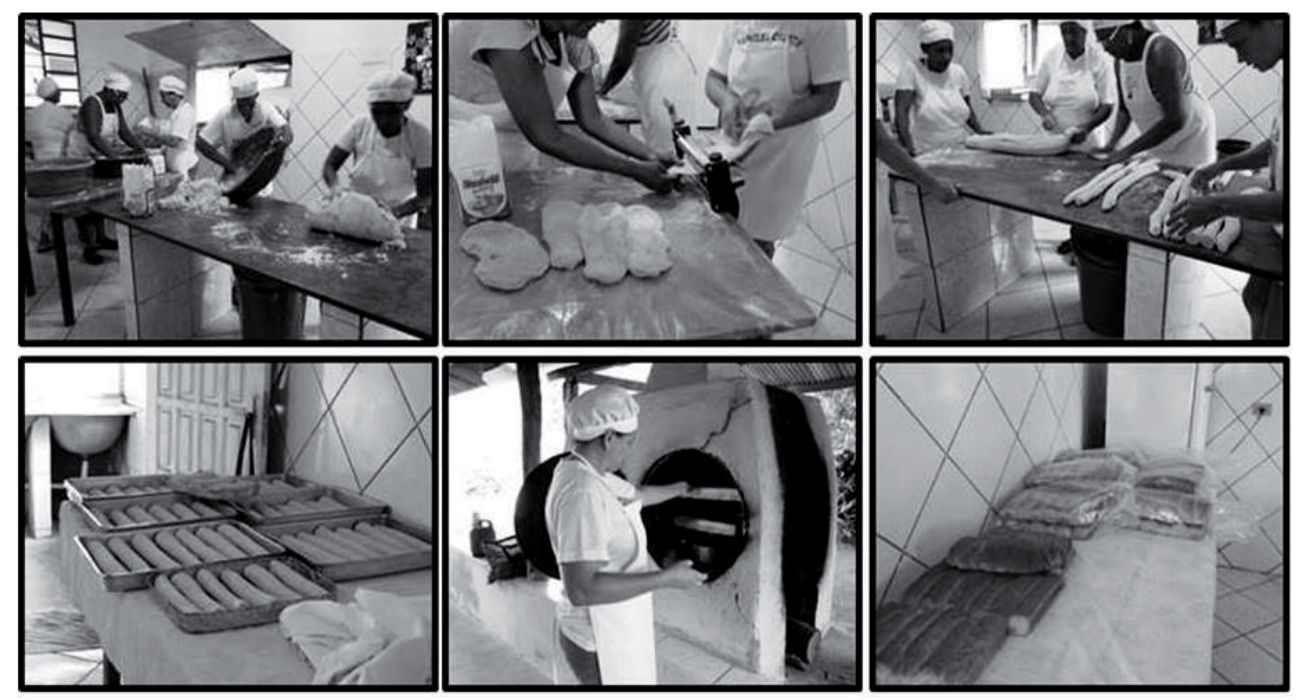

Figura 3 - Produção de pães feita pelo Grupo de Mulheres Amigas do Cerrado no Assentamento Facão/ Furna São José

Fotos: Autor (2013). 
Pimentel et al. (2009) ressaltam que o desenvolvimento de tecnologias adequadas às realidades locais são inovações que têm viabilizado a produção para comércio, sobretudo, pela diminuição dos custos produtivos. Os produtos gerados, depois de embalados são entregues nos dias seguintes. O recolhimento dessa produção fica sob a responsabilidade do motorista do ônibus escolar, ou é coletada por outro motorista de um carro designado pela prefeitura para esse fim e entregue nos estabelecimentos definidos. De acordo com a Conab, em 2005, na região Centro-Oeste do Brasil, eram mais de 185 mil crianças e idosos beneficiados por convênios firmados para a comercialização dos produtos gerados na cadeia do cumbaru. Mior (2005) destaca que esses processos são um conjunto de atividades de agregação de valor, pautadas na agroindustrialização de produtos caseiros, concretizando como novas estratégias de organização e valoração das produtoras, incluindo-as nas cadeias produtivas, valorizando-as; entretanto ainda há uma necessidade de políticas públicas mais aplicáveis e menos burocráticas.
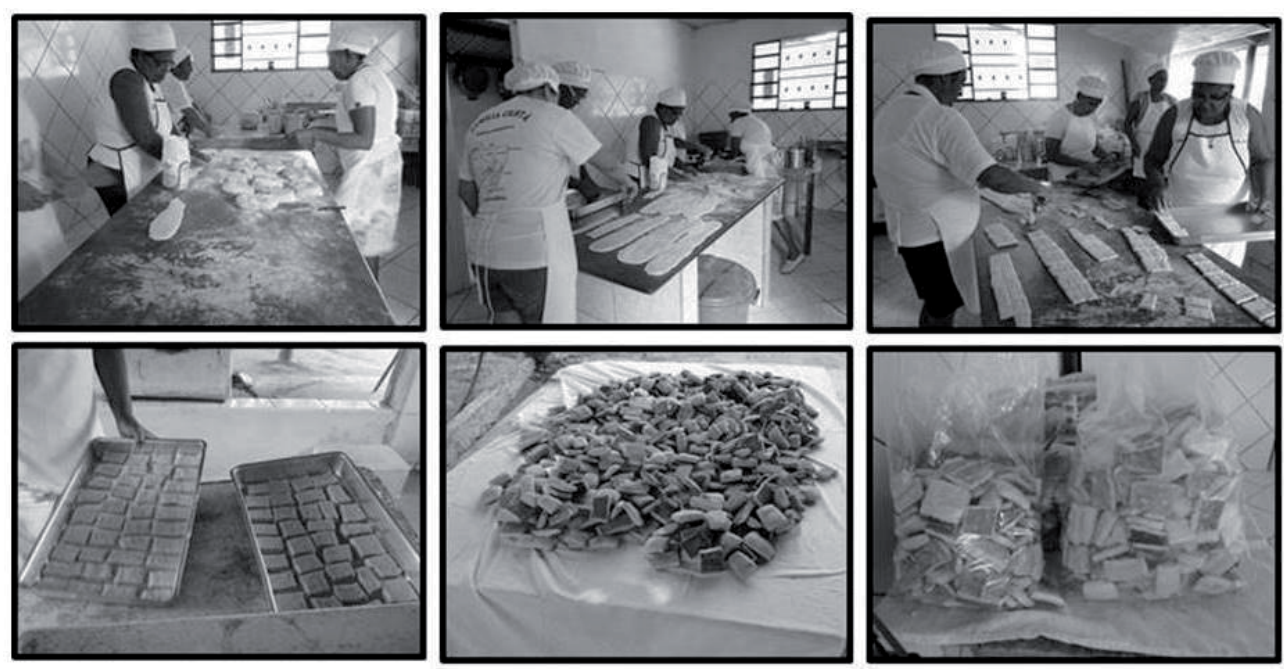

Figura 4 - Produção de bolachas realizada pelo Grupo de Mulheres Amigas do Cerrado no Assentamento Facão/ Furna São José.

Fotos: Autor (2013).

A atividade artesanal de processamento de alimentos, sobretudo feito pela mulher agricultora, evidencia ainda a existência de aspectos culturais associados aos hábitos alimentares dessa região. Mior (2007) esboça que, enquanto o processamento e a transformação de alimentos ocorrem geralmente na cozinha das agricultoras, a agroindústria rural se constitui em um novo espaço e novo empreendimento social e econômico, como é o caso da agroindústria do assentamento Facão/Furna São José.

No que tange à produção e comercialização dos produtos diferenciados, tais como licor, doce, farinha, bombom, paçoquinha, sorvete, bolo, amêndoas torrada com sal ou com açúcar (todos enriquecidos com cumbaru), e do artesanato (coco), estes são realizados conforme demanda de eventos em que as mulheres se inscrevem ou são convidadas a participar, e ainda sob encomenda de outros compradores.

A força do trabalho na produção dos alimentos é estritamente das mulheres do grupo, entretanto os homens (esposos ou companheiros) auxiliam no corte e armazenamento da lenha na unidade de processamento, para abastecimento dos 
fornos de produção.

A cozinha da unidade de processamento, onde são manipulados os produtos, é mantida higienizada, e as agricultoras, ao manipularem os produtos, usam roupas apropriadas, de modo que os visitantes assim também procedam, mantendo sempre em ordem as condições higiênicas da unidade. Mesmo sendo responsáveis pela produção de alimentos na unidade de processamento, as mulheres não deixam de lado sua função de agricultoras, do lar, mães e esposas. Nesse sentido, Campos (1990) considera que a agroindústria familiar não impede a realização de outras atividades na propriedade, consistindo em uma fonte complementar de renda, pois esse modo de produção é possuidor de forte elemento cultural com fundamental importância para o desenvolvimento dos produtos, do assentamento e do grupo de mulheres.

Assim, a agroindústria contribui na vida das agricultoras de modo geral, as mulheres consideram que, desde a formação do grupo e da construção da unidade de processamento (agroindústria), a qualidade de vida se tornou mais viável, e elas têm ganhado espaço nas discussões e autonomia no mercado de trabalho. Wilkinson e Mior (2000) reiteram que a agricultura familiar deveria ocupar um lugar de destaque em processos autônomos de agroindustrialização, eis que, por si só, possui elementos agregadores, com fatores sociais, culturais, econômicos e ecológicos, como forma de fortalecer sua capacidade de reprodução social.

\subsection{Aprimoramento do sistema de produção do assentamento Facão/ Furna São José para incorporação na atividade turística}

A tarefa da agroindústria consiste no beneficiamento ou processamento de produtos agrícolas in natura, sendo esse processo um agregador de valor ao produto da agricultura familiar.

É sabido que esta agregação de valor ao produto é importante sob o aspecto econômico da família, porém Schneider (2003) ressalta que se deve estar atento para inúmeros outros fatores que envolvem esta questão, como logística de distribuição, mercado consumidor, comercialização, tributação, preço e concorrência de outros produtos.

No quadro 1, são apresentados os critérios elencados de acordo com os ambientes e os pontos de análise da produção de alimentos.

\begin{tabular}{|c|c|c|c|c|c|c|}
\hline \multirow{2}{*}{ Ambiente } & \multirow{2}{*}{ Pontos } & \multirow{2}{*}{\multicolumn{2}{|c|}{ Critérios }} & \multicolumn{3}{|c|}{ Valores } \\
\hline & & & & $\mathbf{P}$ & $\mathbf{N}$ & NP \\
\hline \multirow{12}{*}{ Interno } & \multirow{12}{*}{ Fortes } & 01 & Localização & 0,4 & 2 & 0,8 \\
\hline & & 02 & Organização social e inclusão das mulheres & 1 & 3 & 3 \\
\hline & & 03 & Manejo sustentável do cumbaru & 0,5 & 1 & 0,5 \\
\hline & & 04 & Diversidade de produtos diferenciados & 0,9 & 2 & 1,8 \\
\hline & & 05 & Produto com identidade cultural & 0,7 & 2 & 1,4 \\
\hline & & 06 & Produção oriunda do extrativismo & 0,8 & 3 & 2,4 \\
\hline & & 07 & Matéria-prima nativa na região (05 meses - safra) & 0,3 & 2 & 0,6 \\
\hline & & 08 & $\begin{array}{l}\text { Produtos possuem rótulos código de barras e valor } \\
\text { nutricional }\end{array}$ & 0,2 & 4 & 0 \\
\hline & & 09 & $\begin{array}{l}\text { Troca de experiência com outros grupos semelhantes } \\
\text { existentes no país, durante eventos }\end{array}$ & 1 & 3 & 3 \\
\hline & & 10 & $\begin{array}{l}\text { Apoio do sindicato, da Federação de Assistência } \\
\text { Social e Educacional - FASE; do Instituto Sociedade, } \\
\text { População Natureza - ISPN e outras instituições }\end{array}$ & 1 & 3 & 3 \\
\hline & & 11 & Geração de renda complementar & 0,9 & 3 & 2,7 \\
\hline & & 12 & Assistência técnica & 1 & 3 & 3 \\
\hline
\end{tabular}




\begin{tabular}{|c|c|c|c|c|c|c|}
\hline \multirow{2}{*}{ Ambiente } & \multirow{2}{*}{ Pontos } & \multirow{2}{*}{\multicolumn{2}{|c|}{ Critérios }} & \multicolumn{3}{|c|}{ Valores } \\
\hline & & & & $\mathbf{P}$ & $\mathbf{N}$ & $\mathrm{NP}$ \\
\hline \multirow{5}{*}{ Interno } & \multirow{5}{*}{ Fracos } & 01 & Pouco incentivo do poder público local & 0,9 & 2 & 1,8 \\
\hline & & 02 & Acessa apenas três políticas do governo & 0,6 & 1 & 0,6 \\
\hline & & 03 & Capacitação para ofertar produtos visando feiras e eventos & 1 & 3 & 3 \\
\hline & & 04 & Não possui certificação de comércio justo (Fair trade) & 0,8 & 3 & 2,4 \\
\hline & & 05 & $\begin{array}{l}\text { Não estão inseridas na política de inserção aos novos arranjos } \\
\text { produtivos pautado na política de planejamento Estadual - } \\
{\mathrm{MT}+20^{1}}\end{array}$ & 0,8 & 3 & 2,4 \\
\hline \multirow{2}{*}{ Ambiente } & \multirow{2}{*}{ Pontos } & \multirow{2}{*}{\multicolumn{2}{|c|}{ Critérios }} & \multicolumn{3}{|c|}{ Valores } \\
\hline & & & & $\mathbf{P}$ & $\mathbf{N}$ & NP \\
\hline \multirow{20}{*}{ Externo } & & 01 & Burocracia no acesso às políticas de fomento & 0,7 & 1 & 0,7 \\
\hline & Ameaças & 02 & Falta de condições legais para a produção e comercialização & 0,6 & 3 & 1,8 \\
\hline & & 03 & Dificuldade de inserção dos produtos no mercado & 0,4 & 1 & 0,4 \\
\hline & \multirow{17}{*}{ Oportunidades } & 01 & Localização próxima à BR-070 & 1 & 3 & 3 \\
\hline & & 02 & O município de Cáceres faz parte dos 65 Indutores do Turismo & 1 & 3 & 3 \\
\hline & & 03 & Excedente de Produção & 0,1 & 1 & 0,1 \\
\hline & & 04 & Uso de outros frutos para diversificação da produção & 0,6 & 2 & 1,2 \\
\hline & & 05 & $\begin{array}{l}\text { Novos mercados para produtos diferenciados, ecológicos e de } \\
\text { agricultura familiar, etc. }\end{array}$ & 0,7 & 3 & 2,1 \\
\hline & & 06 & Políticas públicas para melhoria e fomento dos produtos & 0,8 & 2 & 1,6 \\
\hline & & 07 & Produto para consumo com acessibilidade & 0,6 & 3 & 1,8 \\
\hline & & 08 & Crescimento na comercialização de produtos diferenciado na região & 0,3 & 1 & 0,3 \\
\hline & & 09 & Premiações para mulheres que desenvolvem trabalhos sustentáveis & 0,1 & 3 & 0,3 \\
\hline & & 10 & Possibilidade de integração a Rota da Piraputanga ${ }^{2}$ & 0,3 & 2 & 0,6 \\
\hline & & 11 & Integração como subproduto da Rota das Águas ${ }^{3}$ & 0,2 & 2 & 0,4 \\
\hline & & 12 & $\begin{array}{l}\text { Produto poderá ser fator agregador do Consórcio Intermunicipal } \\
\text { de Desenvolvimento Econômico, Social, Ambiental e Turístico do } \\
\text { Complexo Nascentes do Pantanal }\end{array}$ & 0,1 & 2 & 0,2 \\
\hline & & 13 & Ampliação do planejamento de marketing & 0,8 & 3 & 2,4 \\
\hline & & 14 & $\begin{array}{l}\text { Distribuição dos produtos no comercio local (lojas de } \\
\text { conveniência, casas de artesanatos e pontos de vendas } \\
\text { estratégicos para atingir o publico alvo - turistas, bem como a } \\
\text { comunidade local) }\end{array}$ & 0,9 & 3 & 2,7 \\
\hline & & 15 & Comercialização diretamente ao consumidor final & 1 & 3 & 3 \\
\hline & & 16 & Nova atividade integrada aos sistemas de produção existente & 0,3 & 3 & 0,9 \\
\hline & & 17 & Potencial de desenvolvimento do turismo rural na região & 0,4 & 3 & 1,2 \\
\hline
\end{tabular}

${ }^{1}$ MT+20 é a política de planejamento estratégico do Estado de Mato Grosso, visando aos próximos 20 anos (2006-2026), sendo que este processo deve ser permanente e contínuo dentro das propostas de promoção para o desenvolvimento sustentável do Estado, com base em um processo ordenado e sistemático de tomadas de decisões, seguindo ações que possam ser executadas para a construção de um futuro desejado, a curto, médio e longo prazo.

${ }^{2}$ A rota da Piraputanga é uma iniciativa de formatar um produto turístico considerando o potencial das propriedades e dos produtos gerados no âmbito da comunidade da região do Córrego da Piraputanga, como forma de valorizar, ofertar e divulgar o artesanato, a gastronomia e as tradições culturais e históricas dos produtores dessa comunidade. A Associação de Produtores Rurais da Piraputanga (APROPIRA) planeja a formatação de um roteiro turístico que contemple as propriedades que tem produção e interesse em abrir as porteiras para visitação, como algumas que já oferecem serviços na área de gastronomia e lazer. Esse roteiro será composto por cerca de 27 produtores (com possibilidade de expansão), localizada município de Cáceres, acessada por meio da MT-343, km 10 a direita, sentido Cáceres - Barra do Bugres.

${ }^{3}$ A Rota das Águas é um roteiro turístico em planejamento composto pelos municípios da região sudoeste matogrossense, que apresentam potenciais semelhantes em relação às belezas naturais, além de serem parecidos no desenvolvimento econômico e populacional, distando $60 \mathrm{~km}$ do município de Cáceres.

${ }^{4}$ O Consórcio Intermunicipal de Desenvolvimento Econômico e Socioambiental Complexo Nascentes do Pantanal, composto por 14 municípios mato-grossenses (Araputanga, Cáceres, Curvelândia, Figueirópolis D’Oeste, Glória D’Oeste, Indiavaí, Jauru, Lambari D’Oeste, Mirassol D'Oeste, Porto Esperidião, Reserva do Cabaçal, Rio Branco, Salto do Céu e São José dos Quatro Marcos), tem por objetivo o planejamento de ações que promovam políticas públicas voltadas ao desenvolvimento socioeconômico e regional, bem como de agroindústrias, da agricultura familiar dos municípios.

Quadro 1 - Avaliação dos critérios que envolvem a produção de alimentos produzidos na unidade de processamento assentamento Facão/Furna São José, Cáceres, MT.

Fonte: Dados da Pesquisa.

Legenda: $\mathrm{P}=$ Peso; $\mathrm{N}=$ Nota; $\mathrm{NP}=$ Nota Ponderada.

INTERAÇÕES, Campo Grande, MS, v. 17, n. 4, p. 591-605, out./dez. 2016. 
No ambiente interno, os quesitos avaliados foram correspondentes a 12 pontos fortes e cinco pontos fracos. Os pontos fortes que foram elencados são os considerados como chave para o desenvolvimento dos produtos, da capacitação, da transferência de tecnologias e da orientação. Isso demonstra o potencial da produção agroindustrial para o desenvolvimento da região. Nesse sentido, Serra et al. (2003) destacaram que esses pontos fortes, também denominados de forças, são potenciais próprio da comunidade, que correspondem a suas características positivas, sendo estas capazes de aumentar a competitividade, entre elas estão: competências, ativos físicos e humanos, alianças e parcerias estratégicas etc.

Os pontos elencados como fracos foram os considerados como cruciais à viabilidade de seus trabalhos e que assegurariam, de certo modo, a permanência dos produtos nos mercados. Apesar de apresentar-se em menor número, geram uma série de preocupações no grupo. Nesse quesito, Serra et al. (2003) ressaltaram que também são denominados de fraqueza e correspondem a algo escasso, falho ou inexistente à comunidade, excluindo-a de situações benéficas, colocando-a em situação de desvantagem competitiva; de modo geral, é quando lhes falta conhecimento técnico, equipamentos, e as instalações são antigas e obsoletas, entre outras.

No que tange ao ambiente externo, foram elencadas três ameaças e 17 oportunidades. As ameaças consideradas por este estudo fazem referência aos gargalos que impedem o acesso a políticas públicas e fomentos, que visam ao desenvolvimento dos produtos, da infraestrutura, das pessoas envolvidas no processo, bem como no assentamento em que vivem.

Os quesitos considerados como ameaças foram definidos como fatores do ambiente externo que repercutem em resultados negativos e independem das ações da comunidade, correspondem a fatores dinâmicos e interativos, potencialmente capazes de prejudicar de forma conjunta, de diversas maneiras e com impactos distintos. Serra et al. (2009) e Manktelow e Carlson (s.d.) afirmam que tais situações demandam esforços no sentido de identificá-los com a maior precisão e antecedência se possíveis, de forma a viabilizar a elaboração de planos de contingência e ações corretivas, como forma de compensar erros e atender as demandas. Contudo não há garantia de segurança, pois esses eventos podem ocorrer de maneira inesperada e demandam, portanto, monitoramento periódico do mercado.

Os critérios correspondentes às oportunidades são as perspectivas de que é viável a inserção desses produtos, bem como da comunidade em novos mercados, inclusive, no seguimento do turismo rural. E são caracterizados por Serra et al. (2003) e Marin e Trentin (2010) como prospecção para o futuro do produto, como sendo positiva, e as atividades da comunidade são eventos favoráveis, sua ocorrência contribui para a melhoria do desempenho da comunidade, reforçando a competitividade e resultando em maiores participações de mercado.

Sendo assim, os critérios apresentados no quadro 1 possibilitam vislumbrar a elaboração de estratégias, para aprimoramento dos elementos que envolvem a produção dos gêneros alimentícios, e conjecturar estratégias de incorporação dos produtos, visando às possibilidades de inserção na cadeia produtiva do turismo. Assim cada linha possibilita a elaboração de uma estratégia de aperfeiçoamento, nos pontos de forças e nas situações de oportunidade e minimizar os pontos fracos e as situações de ameaças, de modo que não influenciem no desenvolvimento dos produtos, criando mecanismos de sobrevivência (CAMPOS, 1990).

A aplicação dos indicadores na matriz SWOT cria um cenário que orienta para a melhoria da gestão da unidade 
de produção a partir das experiências do coletivo de mulheres, agrega-se a esses produtos valor cultural, social e ecológico, apresentando-se como uma forma alternativa de fortalecimento, do potencial da comunidade, para o turismo rural que se desponta para a região, podendo ser visto como possibilidades para o desenvolvimento da localidade, cuja característica vai além de mero espaço rural, ou seja, apresenta recursos naturais conservados, culturais e potencialmente exploráveis para fins turísticos.

Os benefícios que podem ser gerados para a comunidade envolvida, tangem ao desenvolvimento econômico, com geração de emprego e renda agregada ao trabalho da comunidade; no âmbito social, evidencia a questão do trabalho das mulheres, o papel social que as inclui, desconstruindo as questões culturais sobre a exclusão das mulheres; ecologicamente, o manejo adotado para a extração do cumbaru, apresenta-se de forma sustentável, pois são coletadas parte dos frutos que caem no chão, e a outra parte é deixada para alimento dos animais e regeneração da área de coleta.

Drummond (1996), Felfili et al. (2004) e Ribeiro e Walter (2008) em estudos sobre o manejo de espécies frutíferas do Cerrado, afirmaram que esse tipo de atividade empregada é de baixo impacto, fornecendo ao agricultor matéria-prima, a médio e a longo prazo. Esse tipo de manejo, conforme Ribeiro e Walter (2008), é categorizado como uso sustentável do ambiente, de maneira a garantir a continuidade e renovação dos recursos ambientais e processos ecológicos, mantendo a biodiversidade e os demais atributos ecológicos, de forma socialmente justa e economicamente viável.

O processamento dos produtos, o aprimoramento da gestão são fatores que podem contribuir para a melhoria dos produtos diferenciados e sua incorporação na cadeia produtiva do turismo rural. Assim, a agroindustrialização familiar baseada em princípios agroextrativistas, além de gerar renda de forma regular às pessoas envolvidas, inclusão e representatividade da mulher em atividades comunitárias, promove a melhoria da qualidade de vida, a recuperação e preservação dos hábitos culturais e do meio ambiente.

$\mathrm{O}$ aprimoramento dos produtos e a melhoria da gestão da agroindústria é fator importante para a inserção dos produtos na cadeia produtiva do turismo regional, entretanto esse grupo não depende somente de seu potencial produtivo, e sim de influência de diversos fatores do ambiente externo, conforme apontados no quadro 1 . Todavia as possibilidades que são vislumbradas nas oportunidades identificadas influenciarão de forma positiva na inserção dos produtos no mercado, contribuindo na geração e distribuição de renda, na inclusão socioprodutiva do grupo de mulheres da Amigas do Cerrado e na melhoria das condições de vida das envolvidas.

\section{CONSIDERAÇÕES FINAIS}

Os produtos gerados na agroindústria familiar do grupo de mulheres Amigas do Cerrado apresentam potencial para contribuir no desenvolvimento rural da localidade em que são produzidos, mesmo diante das dificuldades de sua inserção nos arranjos produtivos locais.

A incorporação dos produtos em escala municipal tem estimulado os agricultores familiares a permanecer na atividade e a buscar novos mercados. Desse modo, o apoio técnico do sindicato e de órgãos não governamentais tem sido fundamental, pois tem-lhes proporcionado capacitação que por sua vez possibilita-lhes sobressaírem frente às instabilidades e a competitividade do mercado.

Por fim, concluiu-se que produtos diferenciados produzidos pelo grupo "Amigas do Cerrado", no assentamento Facão/Furna São José, apresentam potencial agregador para sua incorporação na 
cadeia produtiva do turismo local, possibilitando que a comunidade envolvida tenha outra vertente de geração de renda complementar, que refletirá na melhoria de suas condições de vida.

\section{REFERÊNCIAS}

ALENTEJANO, P. R. R. Pluriatividade: uma noção válida para a análise da realidade agrária brasileira? In: TEDESCO, J. C. (Org.). Agricultura familiar: realidade e perspectivas. Passo Fundo, RS: Editora EDIUPF, 1999. p. 147-173.

ÁVILA, V. F. Pressupostos para Formação Educacional em Desenvolvimento Local. Interações - Revista Internacional de Desenvolvimento Local, Campo Grande, MS, v. 1, n. 1, p. 63-76, set. 2000.

BRASIL. Relatório de Gestão do Exercício de 2013. Brasília: Embratur, 2014. 378 p. Disponível em: <http://www.turismo. gov.br/sites/default/turismo/o_ ministerio/relatorios/relatorios_2015/ Relatorio_de_Gestao_de_2013_Embratur. pdf>. Acesso em: 4 ago. 2016.

BRASIL. Secretaria de Agricultura Familiar/ Ministério Desenvolvimento Agrário. Programa de Turismo Rural na Agricultura Familiar. Brasília: SAF/MDA, Brasil, 2003.

CAATINGA-CERRADO: comunidades eco-produtivas. O que é mercado diferenciado? [s.d.]. Disponível em: <http://www. caatingacerrado.com.br/perguntasfrequentes/o-que-e-mercado-diferenciado/ $>$. Acesso em: 4 ago. 2016.

CAMPOS, A. Investigación participativa: reflexiones acerca de sus fundamentos metodológicos y de sus aportes al desarrollo social. Cuadernos de agroindustria y economía rural, n. 24, p. 129-146, 1990.

CASTILHO, M. A.; ARENHARDT, M. M.; LE BOURLEGAT, C. A. Cultura e identidade: os desafios para o desenvolvimento local no assentamento Aroeira, Chapadão do Sul, MS. Interações - Revista Internacional de Desenvolvimento Local, Campo Grande, MS, v. 10, n. 2, p. 159-169, jul./ dez. 2009.
DRUMMOND, J. A. A extração sustentável de produtos florestais na Amazônia brasileira: vantagens, obstáculos e perspectivas. Estudos Sociedade e Agricultura, v. 6, p. 115-137, jan./ jun. 1996.

FELFILI, J. M.; RIBEIRO, J.F.; BORGESFILHO, H. C.; VALE, A. T. Potencial econômico da biodiversidade do Cerrado. In: AGUIAR, L. M. S.; CAMARGO, A. J. A. Cerrado: ecologia e caracterização. Planaltina, DF: Embrapa Cerrados, 2004. p. 177-220.

GRAZIANO DA SILVA, J. O que é questão agrária? 4. ed. São Paulo: Brasiliense, 1981.

KASHIMOTO, E. M.; MARINHO, M.; RUSSEFF, I. Cultura, identidade e desenvolvimentolocal: conceitos eperspectivas para regiões em desenvolvimento. Interações Revista Internacional de Desenvolvimento Local, Campo Grande, MS, v. 3, n. 4, p. 35-42, mar. 2002.

LE BOURLEGAT, C. A. Ordem local como força interna de desenvolvimento. Interações - Revista Internacional de Desenvolvimento Local, Campo Grande, MS, v. 1, n. 1, p. 13-20, set. 2000.

MANKTELOW, J.; CARLSON, M. SWOT Analysis - discover new opportunities, manage and eliminate threats. [s.d.]. Disponível em: <http://www.mindtools.com/pages/ article/newTMC_05.htm>. Acesso em: 12 jul. 2013.

MARIANI, M. A. P.; FAGUNDES, M. B. B.; ARRUDA, D. O.;SCHMIDT, V.; CENTURIÃO, D. A. S. Identificação das variáveis - chave para a promoção do desenvolvimento local por meio da atividade turística no município de Corumbá/MS/Brasil: uma aplicação da Análise de SWOT. Pasos: Revista de Turismo y Patrimonio Cultural, v. 12, n. 1, p. 65-78, 2014.

MARIN, M. Z.; TRENTIN, C. E. G. Desenvolvimento rural: análise das agroindústrias familiares de Campinas do SulRS. Perspectiva, v. 34, n. 127, p. 35-51, set. 2010.

MATO GROSSO. Secretaria de Estado de Planejamento e Coordenação Geral. Relatório de Pesquisa Qualitativa. In: PRADO, José Gonçalves Botelho; BERTCHIELI, Regiane; OLIVEIRA, Lucieni Grassi (Org.). Plano de Longo Prazo de Mato Grosso. Cuiabá, MT: 
Central de Texto, 2012. v. II, 99 p. Disponível em: <http:/ /www.seplan.mt.gov.br/mt20/ mt20.htm>. Acesso em: 22 jan. 2013.

MATTEI, L. Programa de aquisição de alimentos da agricultura familiar (PAA): antecedentes, concepção e composição geral do Programa. Cadernos do CEAM, Brasília, v. 7, p. 33-44, 2007.

MELO, N. R. A aplicação da análise SWOT no planejamento turístico de uma localidade: o caso de Araxá, MG. Caderno Virtual de Turismo, v. 11, n. 2, p.164-176, ago. 2011.

MENDES, M. F. Agricultura familiar extrativista de frutos do Cerrado na região sudoeste matogrossense - Brasil: produção e manejo ecológico. 2012. 73 f. Dissertação (Mestrado em Ambiente e Sistemas de Produção Agrícola) - Programa de Pós-graduação em Ambiente e Sistemas de Produção Agrícola. Universidade do Estado de Mato Grosso, Tangará da Serra,MT, 2012.

MIOR, L. C. Agricultura familiar, agroindústria e desenvolvimento territorial. In: COLÓQUIO INTERNACIONAL SOBRE DESENVOLVIMENTO TERRITORIAL SUSTENTÁVEL, 1., Florianópolis, SC, 2007. Anais... Santa Catarina, SC, 2007.

Agricultores familiares, agroindústrias e redes de desenvolvimento rural. Chapecó, SC: Argos, 2005. 338 p.

NEVES, S. M. A.S.; NUNES, M, C, M.; NEVES, R. J. Caracterização das condições climáticas de Cáceres/MT Brasil, no período de 1971 a 2009: subsídios às atividades agropecuárias e turísticas municipais. Boletim Goiano de Geografia, Goiânia, GO, v. 31, n. 2, p. 55-68, jul./dez. 2011.

PESSANHA, L. D. R. Segurança Alimentar como um princípio orientador de políticas públicas: implicações e conexões para o caso brasileiro. 1998. 338 f. Tese (Doutorado em Agricultura Familiar e Desenvolvimento Rural) - Instituto de Ciências Humanas e Sociais - Programa de Pós-graduação Ciências Sociais em Desenvolvimento, Agricultura e Sociedade (ICHS/CPDA) da Universidade Federal do Rio de Janeiro, Rio de Janeiro, 1998.

PIMENTEL, N. M.; DEL MENEZZI, C. H.; GONCALEZ, J. Aproveitamento dos produtos florestais não madeireiros do baru (Dipteryx alata). In: BENSUSAN, N. (Org.).
Unindo sonhos: pesquisas ecossociais no Cerrado. Brasília: Instituto Internacional de Educação do Brasil, 2009. p. 13-328.

RIBEIRO, J. F.; WALTER, B. M. T. As principais fitofisionomias do bioma cerrado. In: SANO, S. M.; ALMEIDA, S. P.; RIBEIRO, J. F. Cerrado: ecologia e flora. Brasília: Embrapa Informação Tecnológica, 2008. p. 151-212.

ROCHA, M. R.; SANTOS, J. C.; LESAMA, M. F. Relato de experiência: percebida e vivida nas relações com agricultores e comerciantes da feira - "Matinfeira", em Matinhos, PR. In: Cadernos de Agroecologia, v. 7, n. 2, p. 1-5, dez. 2012.

RODRIGUES, A. B. (Org.). Turismo e geografia: reflexões teóricas e enfoques regionais. 2. ed. São Paulo: Hucitec, 1999. 274 p.

SCHNEIDER, S. A pluriatividade na agricultura familiar. Porto Alegre, RS: UFRGS, 2003. 245 p.

O desenvolvimento agrícola e as transformações da estrutura agrária nos países desenvolvidos: a pluriatividade. Revista Reforma Agrária - ABRA, v. 24, n. 03, p. 106-132, 1994.

SERRA, F.; TORRES, M. C.; TORRES, A. P. Administração estratégica: conceitos, roteiro prático e estudos de casos. Florianópolis, SC: Insular, 2003. 232 p.

SILIPRANDI, E.; CINTRÃO, R. As mulheres agricultoras no Programa de Aquisição de Alimentos (PAA). Segurança Alimentar e Nutricional, v. 18. n. 2. p. 12-32, 2011.

SILVA, M. A. Produção agroindustrial desenvolvida nos assentamentos da Região Sudoeste Mato-grossense e a atividade de turismo rural. 2014. 81 f. Dissertação (Mestrado em Ambiente e Sistemas de Produção Agrícola) - Programa de Pós-graduação em Ambiente e Sistemas de Produção Agrícola. Universidade do Estado de Mato Grosso, Tangará da Serra, MT, 2014.

SILVA, T. N.; CASIMIRO FILHO, F.; LIMA, P. V. P. S. Turismo rural: uma estratégia de desenvolvimento rural para o Assentamento Coqueirinho - Fortim/ CE. In: CONGRESSO DA SOCIEDADE BRASILEIRA DE ECONOMIA, ADMINISTRAÇÃO E SOCIOLOGIA RURAL, 48., 2010, Campo Grandes, MS. Anais... Brasília: SOBER, 2010. p. 1-20. 
TAKEMOTO,E.;OKADA,I.A.;GARBELOTTI, M. L.; TAVARES, M.; AUED-PIMENTEL, S. Composição química da semente e do óleo de baru (Dipteryx alata Vog), nativo do município de Pirenópolis, Goiás. Revista do Instituto Adolfo Lutz, São Paulo, v. 60, n. 2, p. 113-117, 2001.

TOGASHI, M.; SGARBIERI, V. C. Avaliação nutricional e da proteína e do óleo de semente de baru (Dipteryx alata Vog.). Ciência e Tecnologia dos Alimentos, Campinas, SP, v. 15, n. 1, p. 66-69, jan./jun. 1995.

WILKINSON, J.; MIOR, L. C. Setor informal, produção familiar e pequena agroindústria: Interfaces. Estudos Sociedade e Agricultura, v. 2, n. 13, p. 29-45, 2000.

YORI, C. M. La planificación estratégica y la participación de los actores sociales locales. Interações - Revista Internacional de Desenvolvimento Local, Campo Grande, MS, v.1, n.1, p. 31-40, set. 2000.

\section{Sobre os autores:}

Marcela de Almeida Silva: Turismóloga e Mestre em Ambiente e Sistemas de Produção Agrícola pela Universidade do Estado de Mato Grosso (UNEMAT). Assessora Territorial de Gestão Social do Núcleo de Extensão em Desenvolvimento Territorial da Grande Cáceres (CNPq/MDA/SPM-PR n. 11/2014). Bolsista extensão B do CNPq. E-mail: marcellaalsi@gmail.com

Ronaldo José Neves: Doutor em Geografia pela Universidade Federal do Rio de Janeiro (UFRJ) e Docente da Universidade do Estado de Mato Grosso (UNEMAT). In memoriam. E-mail: rjneves@unemat.br

Sandra Mara Alves da Silva Neves: Doutora em Geografia pela Universidade Federal do Rio de Janeiro (UFRJ) e Docente da Universidade do Estado de Mato Grosso (UNEMAT). E-mail: ssneves@unemat.br 